\title{
Congo River Influence on the Atlantic's Rare Earth Element and Nd/Hf Isotope Distributions
}

\author{
PeEr RAhlF ', GeORgi LAUKert ' , Ed C. HATHORNe ', \\ MARTIN FRANK ' \\ GEOMAR Helmholtz Centre for Ocean Research Kiel, \\ Wischhofstr. 1-3, 24148 Kiel, Germany \\ (glaukert@geomar.de)
}

The Congo River is the second largest river by discharge in the world and a major source of element inputs into the Atlantic. To determine the exact element fluxes and transport mechanisms across its estuary and their impact on Atlantic's element distributions and budgets, we obtained the first combined dissolved neodymium (Nd) and hafnium (Hf) isotope and rare earth element (REE) concentration distributions following the Congo River plume along its flow path off the West African coast and a connected offshore section at $3^{\circ} \mathrm{S}$. The Congo River freshwater is characterized by extraordinarily high $\mathrm{Nd}$ and $\mathrm{Hf}$ concentrations of up to $4000 \mathrm{pmol} / \mathrm{kg}$ and $54 \mathrm{pmol} / \mathrm{kg}$, and by $\mathrm{Nd}(\varepsilon \mathrm{Nd})$ and $\mathrm{Hf}(\varepsilon \mathrm{Hf})$ isotope compositions that range between -15.6 and -16.4 and between 0.35 and -1.4 , respectively. Our offshore data indicate that the fractions of riverine REEs and $\mathrm{Hf}$ that pass the estuarine filter in dissolved form are significantly larger for the Congo than for other rivers, and that conservative mixing of riverine $\varepsilon_{\mathrm{Nd}} / \varepsilon \mathrm{Hf}$ and $\mathrm{REE} / \mathrm{Hf}$ concentrations with ambient surface seawater occurs for at least $1000 \mathrm{~km}$ to the northwest of the river mouth. Release from or exchange with particles at lower salinities cannot be assessed for the surface waters due to the lack of data, but intermediate and deep waters below the plume and in the open northern Angola Basin have $\varepsilon_{\mathrm{Nd}}$ values inconsistent with values expected from large-scale water mass mixing indicating unradiogenic $\mathrm{Nd}$ release from Congoderived particles. REE enrichment in bottom waters of the northern Angola Basin is attributed to release from particles due to sediment resuspension. 